\title{
Conservative management of hydropneumothorax in a 4-year-old child with pneumonia
}

\author{
Carsten Krueger MD, Theo J. Moraes MD, Stacey Bernstein MD
}

n Cite as: CMAJ 2021 August 23;193:E1350. doi: 10.1503/cmaj.202468

A healthy, fully immunized 4-year-old girl was admitted to hospital after 1 week of fever and respiratory distress, when her chest radiograph showed right-sided pneumonia with large pleural effusion (Appendix 1, Figure S1, available at www.cmaj.ca/lookup/doi/10.1503/cmaj.202468/tab-related-content). She was treated with ceftriaxone and discharged 7 days later after a negative blood culture, with a prescription for 2 weeks of oral amoxicillin-clavulanate. Eight days after discharge she developed a cough and right-sided chest pain and returned to hospital. She appeared well with heart rate 120 beats/min, respiratory rate 20 breaths $/ \mathrm{min}$, temperature $36^{\circ} \mathrm{C}$ and oxygen saturation $97 \%$. We found decreased breath sounds on auscultation of the right chest. Chest radiograph showed a right-sided hydropneumothorax (Figure 1). We admitted her for observation and intravenous ceftriaxone. Daily chest radiographs over 2 days showed improvement, and she remained clinically well. After consulting with respirology and interventional radiology, we decided that procedural intervention or advanced imaging would not provide therapeutic benefit. The patient was discharged from hospital, ultimately receiving a total of 6 weeks of antibiotics and she remained asymptomatic. She also had repeat chest radiographs and clinic appointments booked at 5 days and 2 weeks after discharge. Eight months later, her chest radiograph was completely normal (Appendix 1, Figure S2).

Hydropneumothorax is an uncommon complication of pneumonia characterized by the accumulation of fluid and air within the pleural space, thought to result from an air leak through necrotic lung parenchyma. ${ }^{1}$ The few pediatric cases reported have been managed with chest tube insertion until resolution, requiring a prolonged hospital stay..$^{1,2}$ We considered that, because our patient was clinically well, close follow-up was low risk compared to chest tube insertion. Risks of chest tube insertion in children include those associated with sedation and anesthesia, pain, development of bronchopleural fistula, and prolonged hospital stay. ${ }^{3}$ Chest tubes are clearly indicated for patients with tension hydrothorax, worsening hydropneumothorax, or respiratory distress. This case shows that conservative management with inpatient observation, followed by subsequent close clinical and radiographic outpatient follow-up, can lead to successful resolution of hydropneumothorax complicating pneumonia in otherwise healthy children. Candidates for conservative management are patients who are clinically stable with evidence of improvement on serial chest radiographs and reliable guardians who can support close outpatient follow-up.

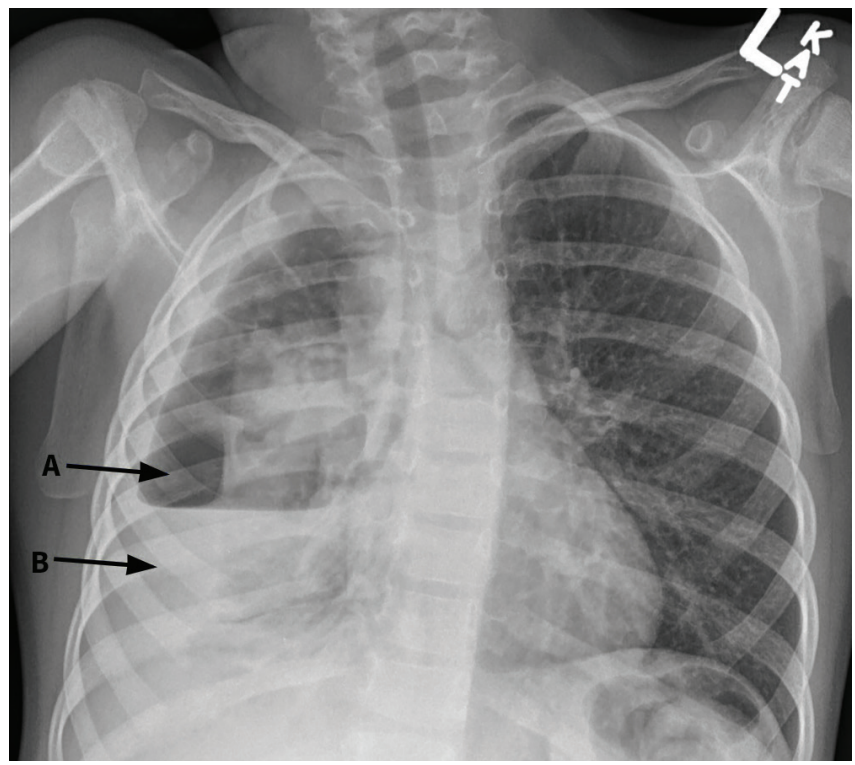

Figure 1: Chest radiograph of a 4-year-old girl, taken during second hospital admission and showing (A) substantial right lung collapse and (B) hydropneumothorax.

\section{References}

1. Miller JC, Boyce TG. Hydropneumothorax as a complication of necrotizing pneumonia in a young girl. Clin Case Rep 2019;7:1559-61.

2. Ortega C, Gonzales C, Soto-Martinez ME, et al. Hydropneumothorax in children: a rare complication of a bacterial pneumonia. Case Rep Pediatr 2016;2016. doi: 10.1155/2016/8097105.

3. Kiliç N, Çelebi S, Gürpınar A, et al. Management of thoracic empyema in children. Pediatr Surg Int 2002;18:21-3.

\section{Competing interests: None declared.}

This article has been peer reviewed.

The authors have obtained consent from the patient's family.

Affiliation: Department of Pediatrics, Temerty Faculty of Medicine, University of Toronto, Toronto, Ont.

Content licence: This is an Open Access article distributed in accordance with the terms of the Creative Commons Attribution (CC BY-NCND 4.0) licence, which permits use, distribution and reproduction in any medium, provided that the original publication is properly cited, the use is noncommercial (i.e., research or educational use), and no modifications or adaptations are made. See: https://creativecommons.org/ licenses/by-nc-nd/4.0/

Correspondence to: Stacey Bernstein, Stacey.bernstein@sickkids.ca 